\title{
Comparative study of patch antenna loaded with slot split-ring resonators on different substrate materials
}

\author{
A. Bendaoudi ${ }^{1} \cdot$ Z. $_{\text {. Mahdjoub }}{ }^{1}$
}

Received: 19 September 2016 / Accepted: 19 July 2017 / Published online: 29 July 2017

(C) The Author(s) 2017. This article is an open access publication

\begin{abstract}
This paper presents square patch antenna loaded with slot split-ring resonators. Moreover, this paper discusses the performances of various dielectric substrates, having dielectric constants ranging from 2 to 5. Different substrate has been used to design the antenna such as Bakelite, Rogers RO 4232 and RT Duroid with dielectric constant of 4.8, 3.2 and 2.2, respectively. The resonance frequency is $2.25 \mathrm{GHz}$; these antennas are suitable for S-band and communication applications. The effect of change in substrate material on the performance of antenna is compared, in terms of reflection coefficient, bandwidth, directivity and radiation pattern.
\end{abstract}

Keywords Square patch antenna - Slot split-ring resonators . Directivity $\cdot$ Radiation pattern $\cdot$ Reflection coefficient

\section{Introduction}

The field of electromagnetics had a tremendous opening with the introduction of artificial negative index medium (metamaterials) and its feasibility in microstrip patch antenna structures [1]. The first researches concerning the properties of metamaterials are made by Victor Veselago in 1968. Later Smith [2] implements first left-handed materials consist of periodic split-ring resonators (SRR's) and long strips. Splitring resonators (SRRs) responsible for negative permeability and metal strip responsible for negative permittivity are used to improve both gain and directionality of patch antenna [3].

\section{A. Bendaoudi}

aminabendaoudi@yahoo.fr

Z. Mahdjoub

mahdjoubz@yahoo.com

1 Electromagnetic Photonics Optronics Laboratory (EPOL), University of Sidi Bel Abbès, 22000 Sidi Bel Abbès, Algeria
However, in microstrip technology, SRR particles exhibit weak $\mathrm{H}$-field excitation by the incident field, as in a CoPlanar Waveguide (CPW) structure. Its specific effect is not noticeable by maintaining size $[4,5]$. In order to overcome these limitations, a new configuration of the radial E-field excites the particle and has been introduced [5,6]. Slot splitring resonators (SSRR) is the dual form of SRR. Because of their small size, complementary SRRs are called sub-lambda structures. Due to this fact, a super-compact structure can be implemented using complementary SRRs [7] since this structure is etched on the ground plane, under the conductor strip position, and is excited by the electric field, induced by the conductor line [8]. The main difference between SRR and SSRR is that SRR has negative permeability characteristics, while complementary SRR has negative permittivity characteristics [9].

The SSRR has brought important innovations in the field of microwave and optical. Other applications have emerged in the field couplers and filters. Another evolving area today concerns the antennas. It has been proven by example that it was possible to improve the performance of a square patch antenna thanks to SSRR in terms of directivity and of gain. The choice of parameter values of a patch antenna generally determines the type of application we want to consider in microstrip technology.

A microstrip patch antenna is made up of a radiating patch on one side of dielectric substrate while has a ground plane on the other side [10]. Substrate is located over a large metallic sheet called ground plane [11]. The suitable substrate is the one with a low dielectric constant, a large thickness compared to the operating wavelength and low loss (low $\tan \delta$ ) because in the realization of microwave circuits, the goal is to minimize the radiation of the line in free space and therefore have a substrate which the electromagnetic energy is concentrated in the dielectric (more precisely in the cavity formed 


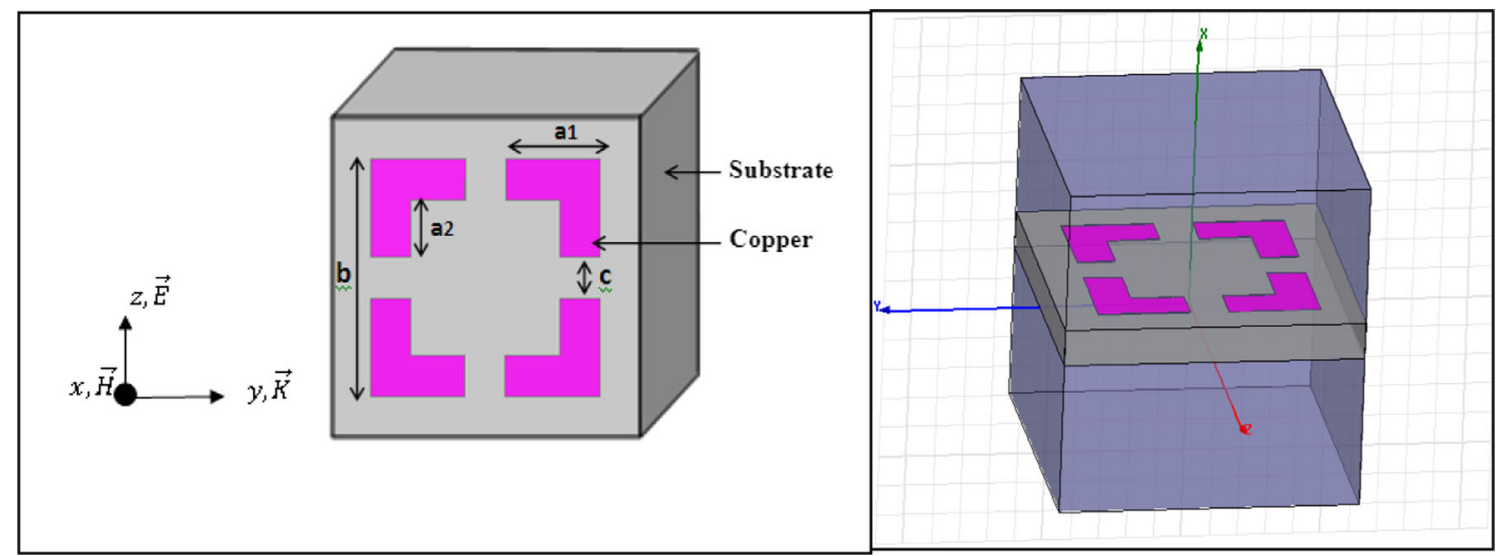

Fig. 1 Representation and dimensions of SRR cell unit

by the metal strip and the ground plane). So a thick substrate increases the power radiated by the antenna, reduces losses by Joule effect and improves the bandwidth of the antenna. Permittivity of substrate is a critical parameter in controlling band width, efficiency, and radiation pattern of patch antenna. However, higher dielectric constant also reduces bandwidth and radiation efficiency.

The material used for substrate can be dielectric constant in the range of $2.2 \leq \varepsilon_{r} \leq 12$ [12]. Patch antenna radiates primarily because of the fringing fields between the patch edge and the ground plane.

This work is conducted in S-band [ $2 \mathrm{GHz} ; 4 \mathrm{GHz}]$. In this frequency band are located commercial and scientific applications such as radar of local air traffic and weather and naval radar. We propose to study a patch antenna loaded with slot split-ring resonators on three substrate types. We show that the substrate has an influence on the reflection coefficient, the directivity and the gain of the square patch antenna.

This paper is organized as follows. In Sect. 2, the antenna model is introduced. Section 3 demonstrates the results of the paper as a whole and a comparison between three different substrates in terms of the reflection coefficient, bandwidth, directivity and gain. Finally, some conclusions are drawn in Sect. 4.

\section{Antenna configuration}

\subsection{Proposed split-ring resonators cell}

To understand the functioning of SSRR, apply Babinet's principle which was then generalized by Booker [13]. Since the SSRR is the dual of the SRR, it is by the virtue of the duality principle. The basic mechanism of SRR and SSRR is same except for excited the axial electric field [14]. Figure 1 shows the geometry of SRR.

Parametric representation of the patch antenna is given in Table 1 below:
Table 1 Parameters of slot split-ring resonator

\begin{tabular}{ll}
\hline Parameters & Dimensions $(\mathrm{mm})$ \\
\hline$a_{1}$ & 3.3 \\
$a_{2}$ & 2.1 \\
$b$ & 8 \\
$c$ & 1.4 \\
\hline
\end{tabular}

To obtain complementary of split-ring resonator structure, replace the copper parts with substrate material and the substrate material with copper parts [15].

The structure of SRR has been dimensioned for resonance in the vicinity $2.25 \mathrm{GHz}$. This resonator is etched on different substrates namely RT Duroid dielectric material with relative permittivity $\left(\varepsilon_{r}\right)$ of 2.2, Rogers with $\left(\varepsilon_{r}\right)$ of 3.2 , Bakelite $\left(\varepsilon_{r}\right)$ of 4.4 and with thickness (h) of $1.4 \mathrm{~mm}$ is chosen.

Figure 2 shows the reflection and transmission coefficients as a function of the frequency of an SRR cell unit for different proposed substrates.

When using a substrate in RT Duroid, we observe on the curve of $\mathrm{S}_{11}$ a resonant frequency at $1.78 \mathrm{GHz}$ with a transmission of the order of $-42 \mathrm{~dB}$. On the $\mathrm{S}_{21}$ curve, we observe a high bandwidth transmission at $1.27 \mathrm{GHz}$.

For a substrate of type Rogers, we observe on the curve of $\mathrm{S}_{11}$ a resonant frequency at $1.42 \mathrm{GHz}$ with a transmission of the order of $-48 \mathrm{~dB}$. On the $\mathrm{S}_{21}$ curve, we observe a high bandwidth transmission at $1.83 \mathrm{GHz}$.

If the substrate is Bakelite, we observe on the curve of $\mathrm{S}_{11}$ a resonant frequency at $1 \mathrm{GHz}$ with a transmission of the order of $-10.83 \mathrm{~dB}$. On the $\mathrm{S}_{21}$ curve, we observe a high bandwidth transmission at $1.25 \mathrm{GHz}$.

\subsection{Patch antenna loaded with SSRR}

A simple microstrip patch antenna consists of a conducting patch and ground plane between them is a dielectric medium 
Fig. 2 Simulated reflection and transmission coefficient. a Reflection and transmission coefficient of RT Duroid substrate $\left(\varepsilon_{r}=2.2\right)$. $\mathbf{b}$

Reflection and transmission coefficient of Rogers substrate $\left(\varepsilon_{r}=3.2\right)$. $\mathbf{c}$ Reflection and transmission coefficient of Bakelite substrate $\left(\varepsilon_{r}=4.8\right)$

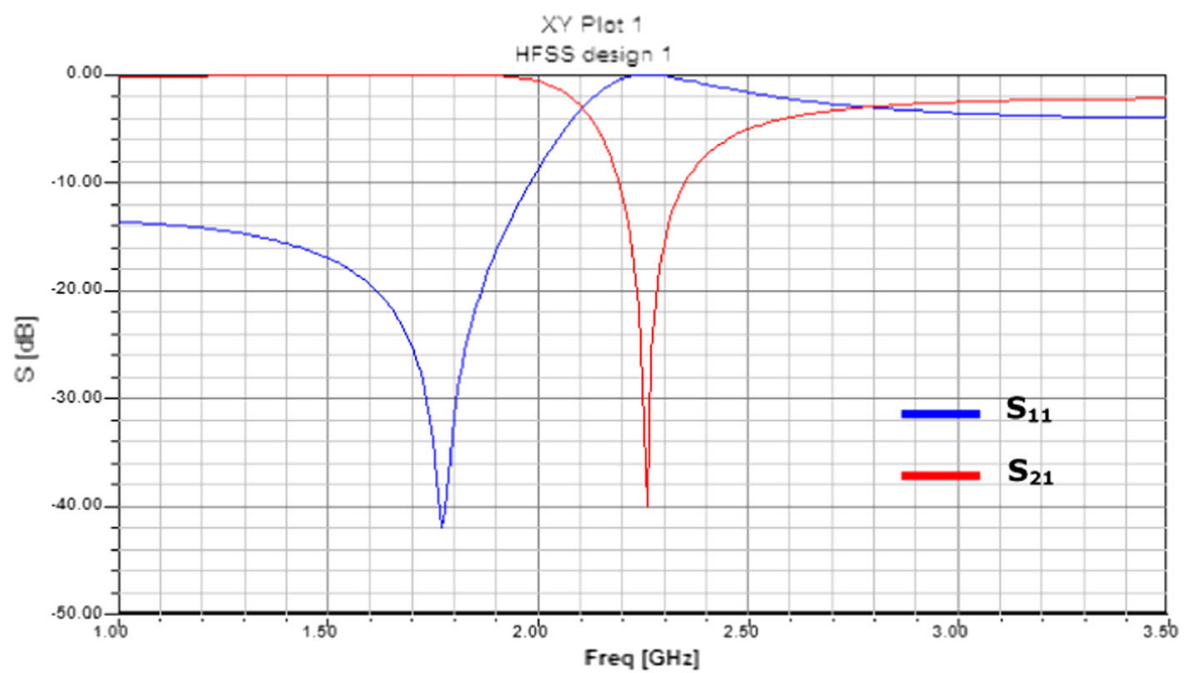

(a)

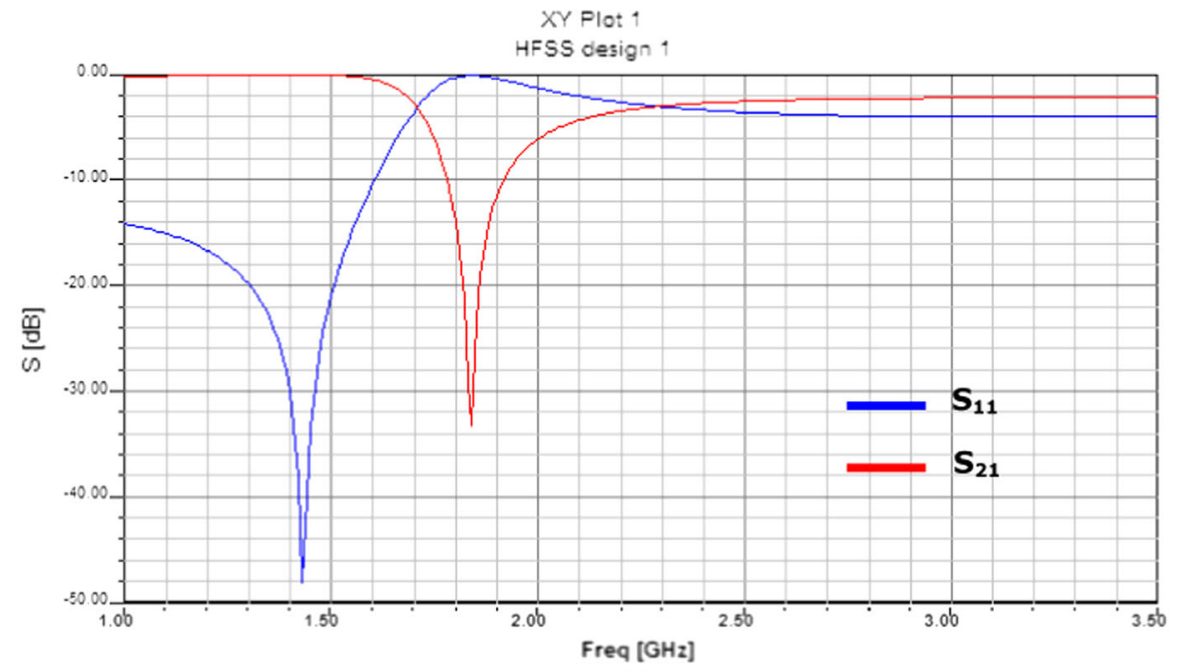

(b)

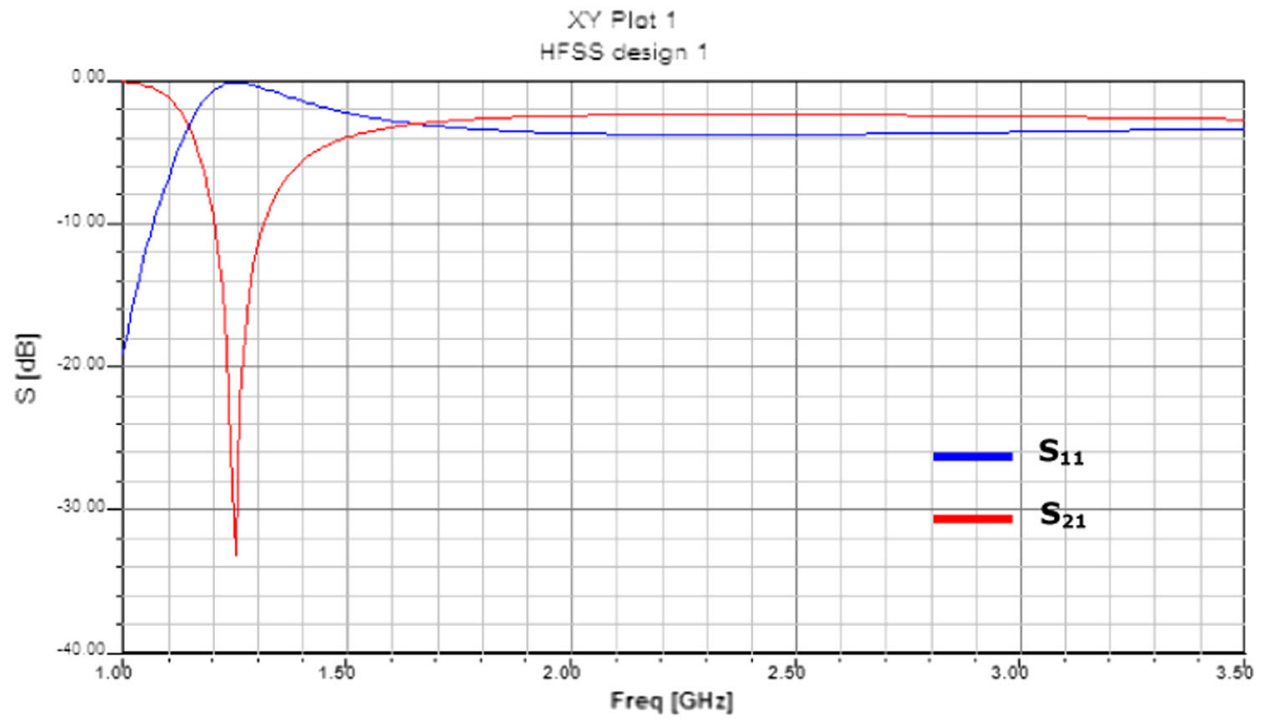

(c) 


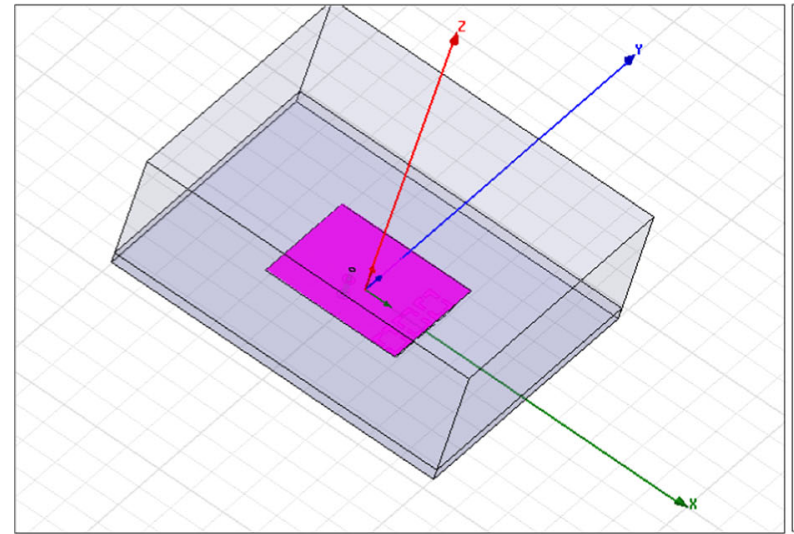

(a)

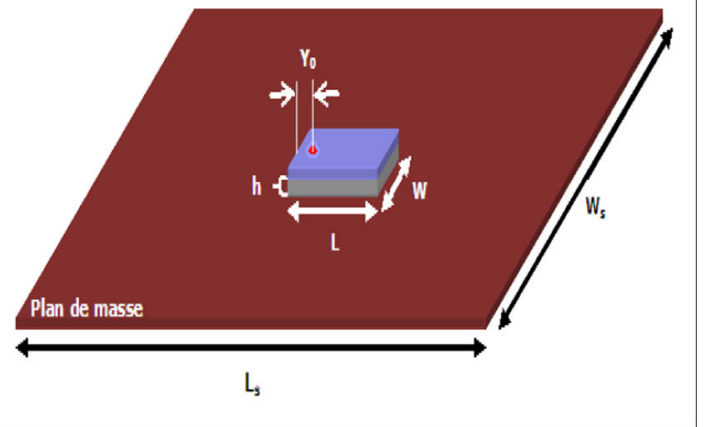

(b)

Fig. 3 Square patch antenna: a modeled square patch antenna in HFSS, b square patch antenna dimensions

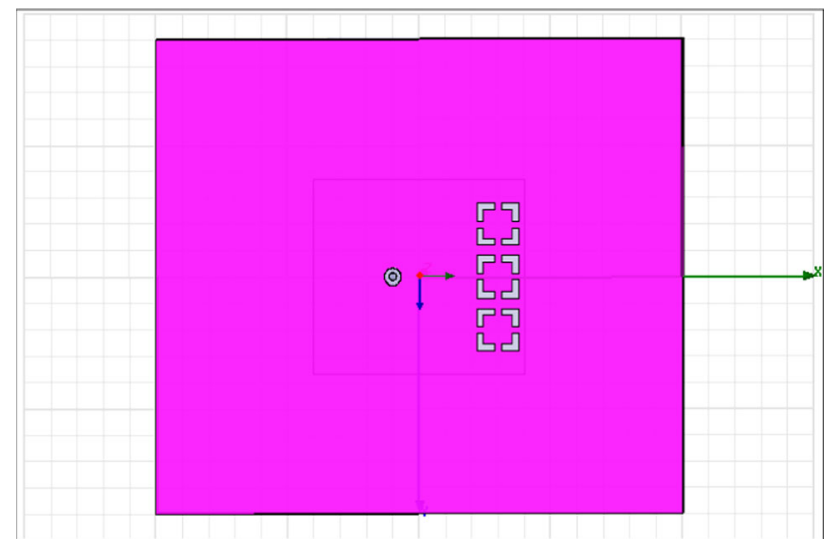

Fig. 4 Back ground of antenna with SSRR in HFSS

called the substrate having a particular value of dielectric constant [16].

The resonant frequency of the microstrip patch antenna can be calculated as under [17-19]:

$f_{r}=\frac{C}{2 w} \sqrt{\frac{2}{\varepsilon_{r}+1}}$ where $w$ : width of the patch, $C$ : speed of light, $\varepsilon_{r}$ : value of the dielectric substrate.

The value of the effective dielectric constant $\varepsilon_{\text {reff }}$ is calculated using the following equation [17-19]:

$\varepsilon_{\mathrm{reff}}=\frac{\varepsilon_{r}+1}{2}+\frac{\varepsilon_{r}-1}{2}\left[1+12 \frac{h}{w}\right]^{-1 / 2}, w / h>1$

Due to fringing, electrically the size of the antenna is increased by an amount of $\Delta L$. Therefore, the actual increase in length $\Delta L$ of the patch is to be calculated using the following equation [17-19]:

$\frac{\Delta L}{h}=0.412 \frac{\left(\varepsilon_{\text {reff }}+0.3\right)\left(\frac{w}{h}+0.264\right)}{\left(\varepsilon_{\text {reff }}-0.258\right)\left(\frac{w}{h}+0.8\right)}$

where $h$ height of the substrate The length $L$ of the patch is now to be calculated using the below mentioned equation [17-19]:

$L=\frac{C}{2 f_{r} \sqrt{\varepsilon_{\text {reff }}}}-2 \Delta L$
Table 2 Parameters of square patch antenna loaded with SSRR on different substrates

\begin{tabular}{llll}
\hline & RT Duroid & Rogers RO 4232 & Bakelite \\
\hline Effective dielectric constant $\varepsilon_{r}$ & 2.2 & 3.2 & 4.8 \\
Tangent loss & 0.0009 & 0.0018 & 0.002 \\
Resonant frequency $(\mathrm{GHz})$ & 2.25 & & \\
Width of patch $W(\mathrm{~mm})$ & 40 & 40 & 30 \\
Length of patch $L(\mathrm{~mm})$ & 30 & 37 & 50 \\
Thickness of substrate $h(\mathrm{~mm})$ & 32 & & \\
Substrate length $L_{s}(\mathrm{~mm})$ & 75 & 56 & 63 \\
Substrate width $W_{s}(\mathrm{~mm})$ & 49 & 59 & 59 \\
$X_{0}(\mathrm{~mm})$ & 20 & 20 & 15 \\
$Y_{0}(\mathrm{~mm})$ & 10 & 8 & 20 \\
\hline
\end{tabular}


Fig. 5 Simulated reflection coefficient of square patch antenna loaded with SSRR. a Reflection coefficient of RT Duroid substrate $\left(\varepsilon_{r}=2.2\right)$. b Reflection coefficient of Rogers substrate $\left(\varepsilon_{r}=3.2\right)$. c

Reflection coefficient of

Bakelite substrate $\left(\varepsilon_{r}=4.8\right)$

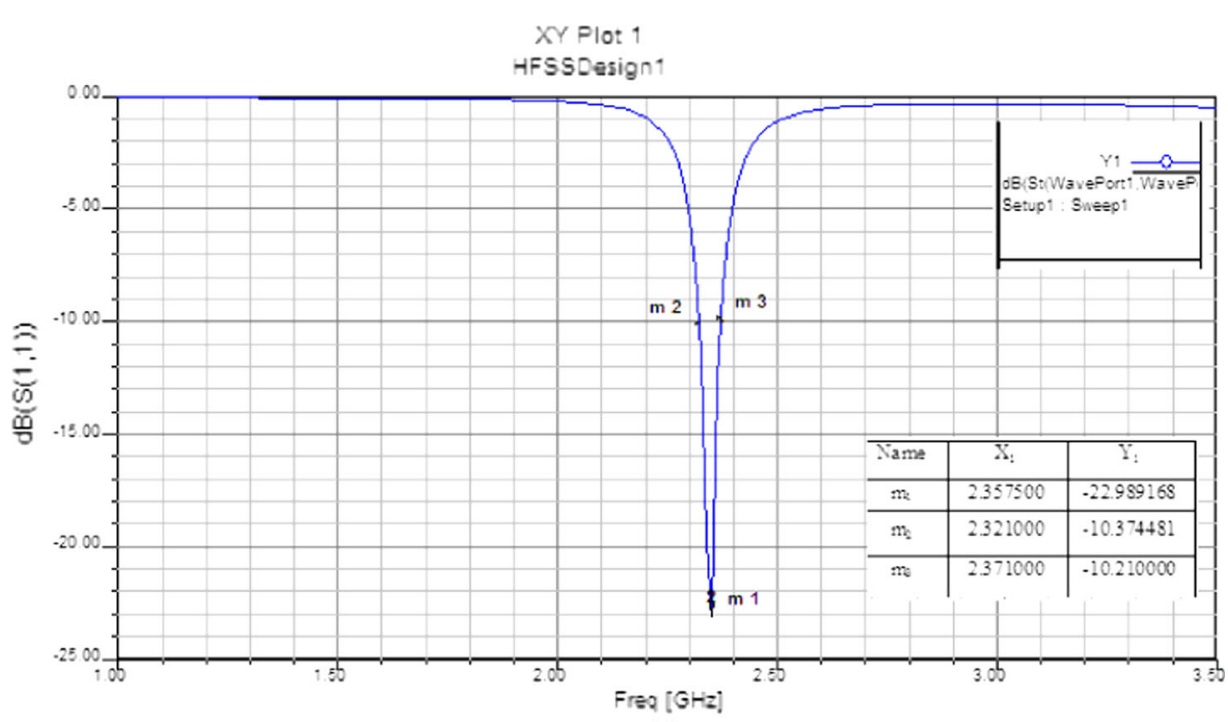

(a)

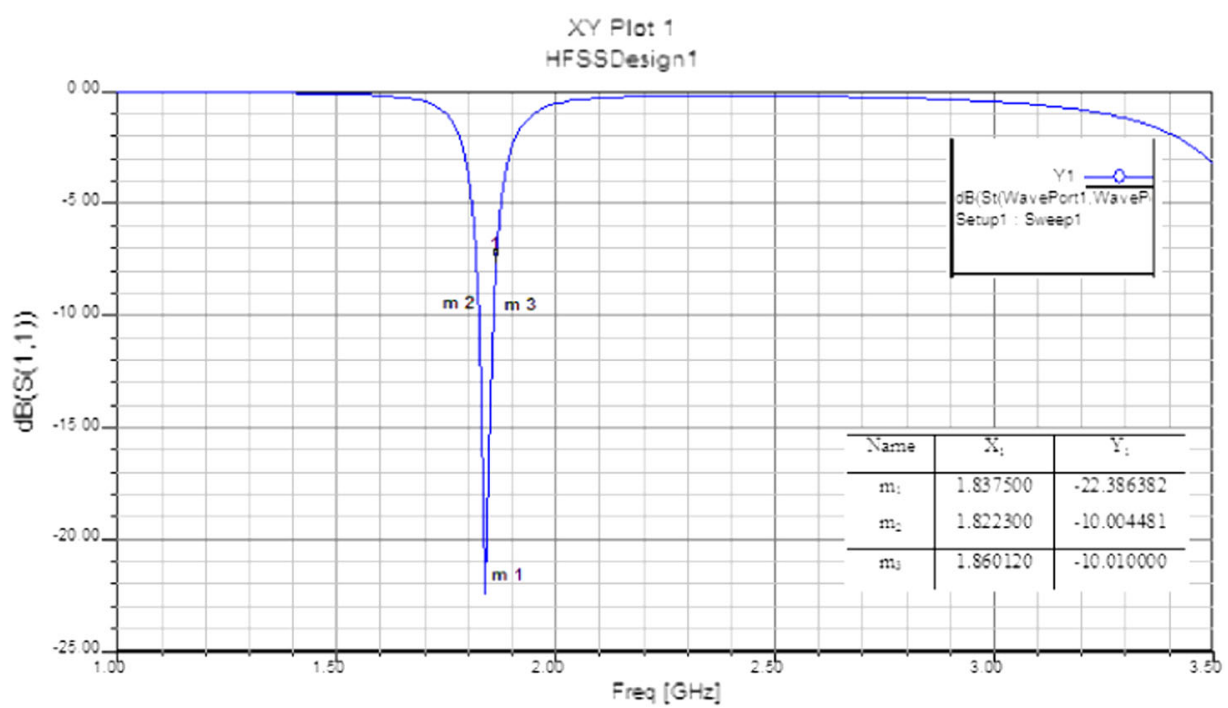

(b)

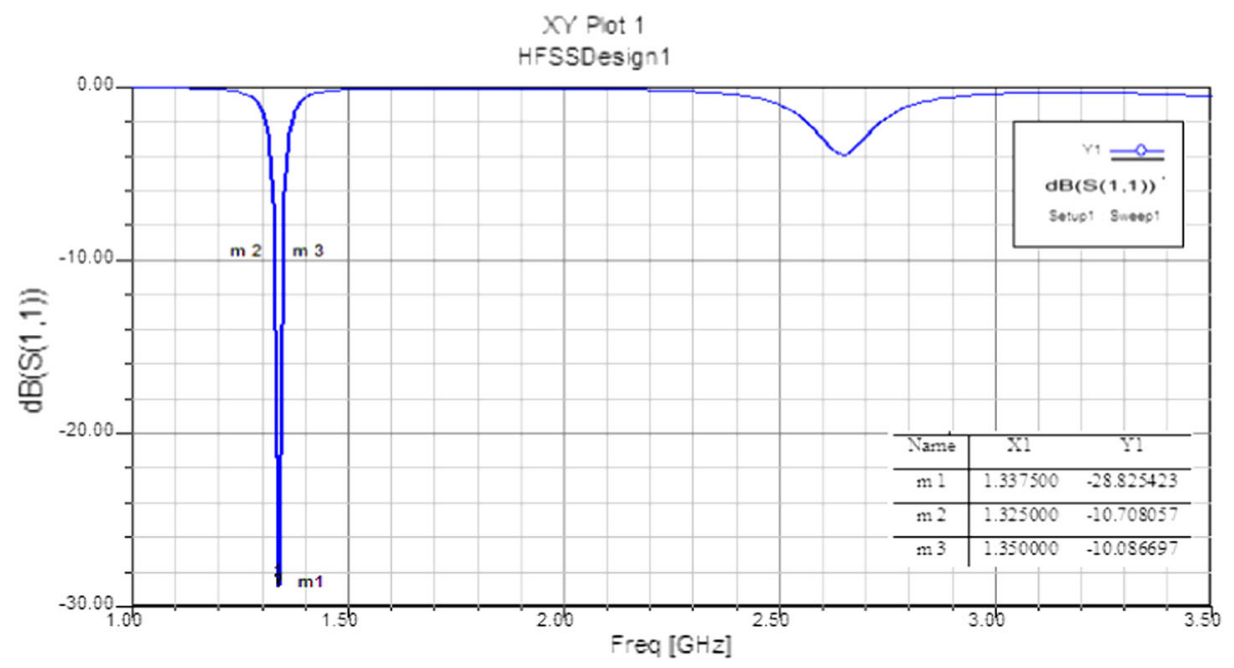

(c) 
Fig. 6 Simulated directivity of square patch antenna loaded with SSRR. a Directivity for RT

Duroid substrate $\left(\varepsilon_{r}=2.2\right)$. b Directivity for Rogers substrate $\left(\varepsilon_{r}=3.2\right)$. c Directivity for Bakelite substrate $\left(\varepsilon_{r}=4.8\right)$

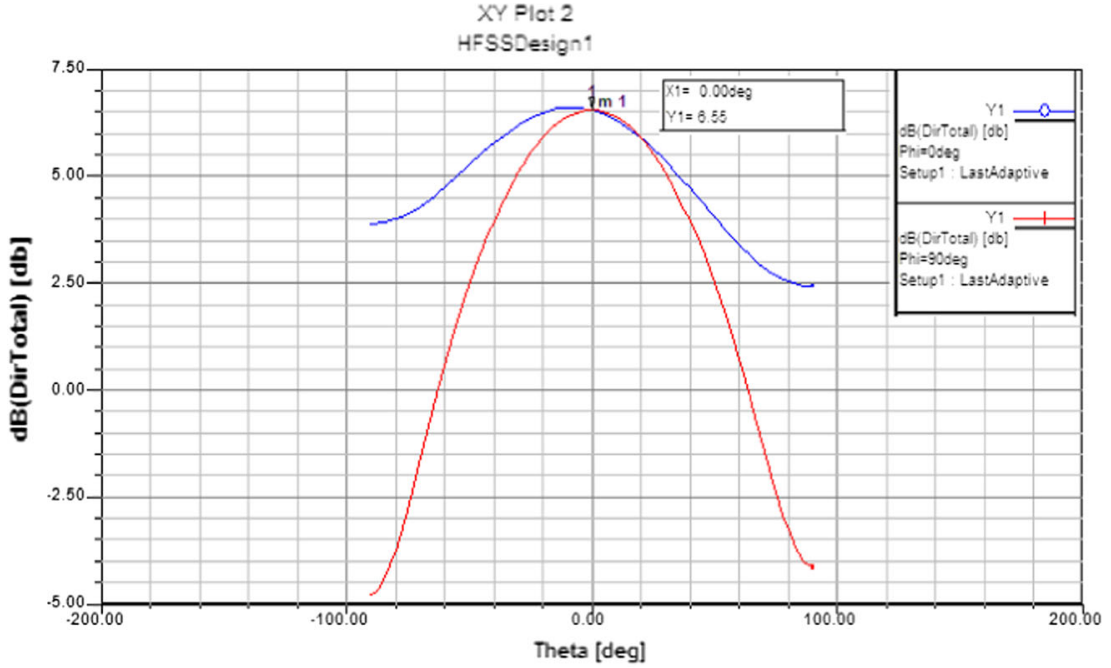

(a)

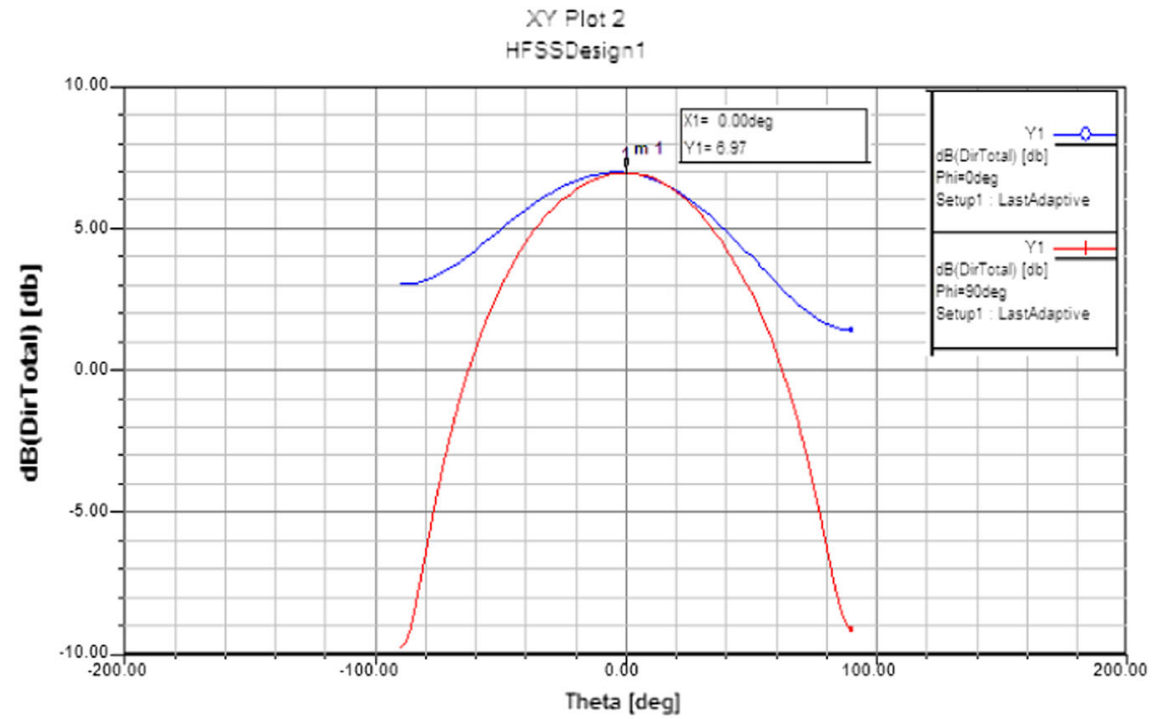

(b)

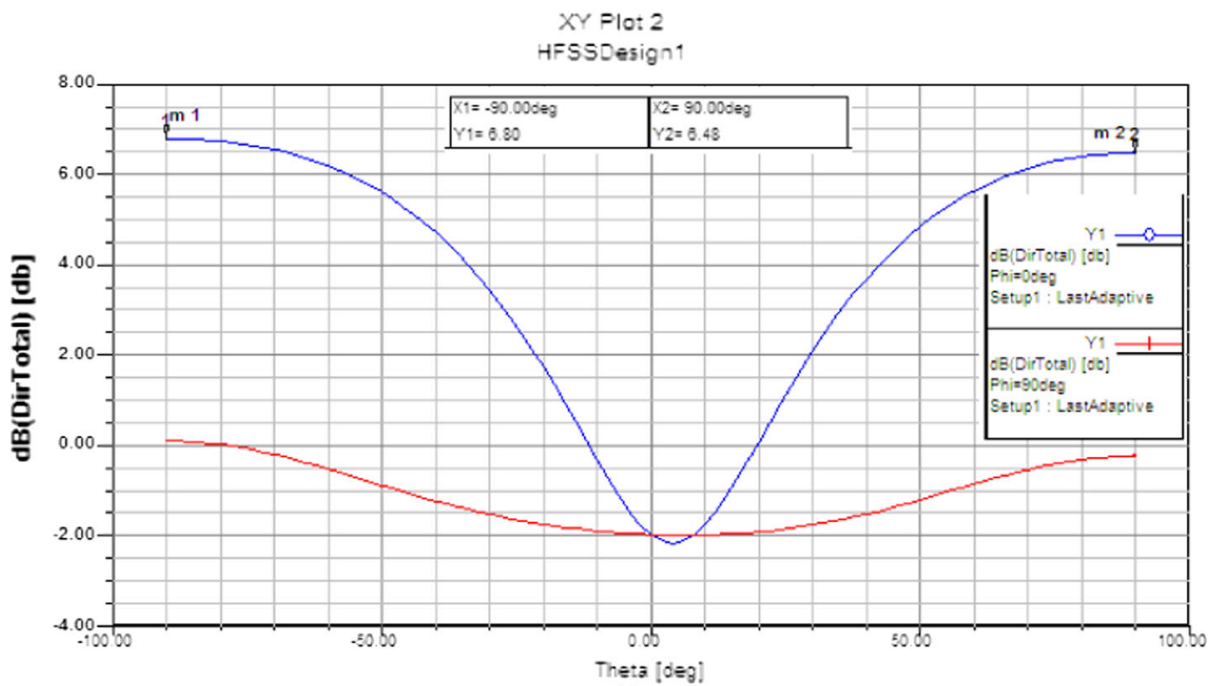

(c) 
Now the dimensions of a patch are known. The length and width of a substrate is equal to that of the ground plane. The length of a ground plane $L_{g}$ and the width of a ground plane $w_{g}$ are calculated using the following equations [20]:

$$
\begin{aligned}
& L_{g}=6 h+L \\
& w_{g}=6 h+w
\end{aligned}
$$

The proposed antenna consists of radiating element copper and substrate between the radiating element and ground plane. The square patch antenna is fed by a coaxial cable with a characteristic impedance of $50 \Omega$. Figure 3 shows the radiated patch.

In planar technology, the E-field is normal to the ground plane and the patch geometry on the trace. Thus, the SSRR is etched in the ground plane such that they can be easily excited by an E-field parallel to their axes.

The patch antenna loaded with and slot split-ring resonator (SSRR) structure is represented below (Fig. 4).

The structure has been dimensioned for resonance in the vicinity $2.25 \mathrm{GHz}$. This antenna is designed on different substrates namely RT Duroid dielectric material with relative permittivity $\left(\varepsilon_{r}\right)$ of 2.2 , Rogers with $\left(\varepsilon_{r}\right)$ of 3.2 , Bakelite $\left(\varepsilon_{r}\right)$ of 4.4 and with thickness $(h)$ of $32 \mathrm{~mm}$ is chosen. The characteristics of substrates used in our simulation are listed in Table 2.

\section{Results and discussion}

\subsection{Reflection coefficient}

For the simulations, we used HFSS. The coaxial feed source is powered by a wave port. The model area is surrounded by an absorbent box (radiation). In the following Fig. 5, we see the result of the reflection coefficient for the three different substrates.

Figure 5a indicates the reflection coefficient for RT Duroid gives about $-22.98 \mathrm{~dB}$ and resonance frequency at $2.35 \mathrm{GHz}$. The reflection coefficient value of Rogers substrate is $-22.38 \mathrm{~dB}$ shown in Fig. $5 \mathrm{~b}$ and resonance frequency at $1.83 \mathrm{GHz}$. Figure $5 \mathrm{c}$ shows the reflection coefficient for Bakelite gives about $-28.82 \mathrm{~dB}$ and resonance frequency at $2.33 \mathrm{GHz}$. It is noted also that the bandwidth is inversely proportional to the reflection coefficient.

\subsection{D-directivity}

Figure 6 shows the directivity gain of the antenna in three different substrates. We will use the following angles $\varphi$ and $\theta$ known spherical coordinates ( $\varphi$ represents the angle about the $\mathrm{X}$-axis in the $\mathrm{XY}$ plane; $\theta$ represents the angle to the $\mathrm{Z}$ axis).

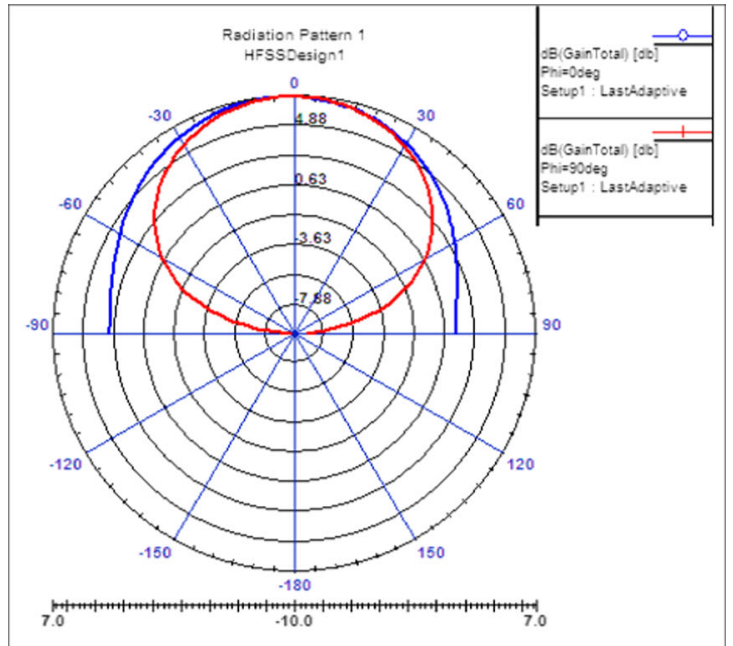

(a)

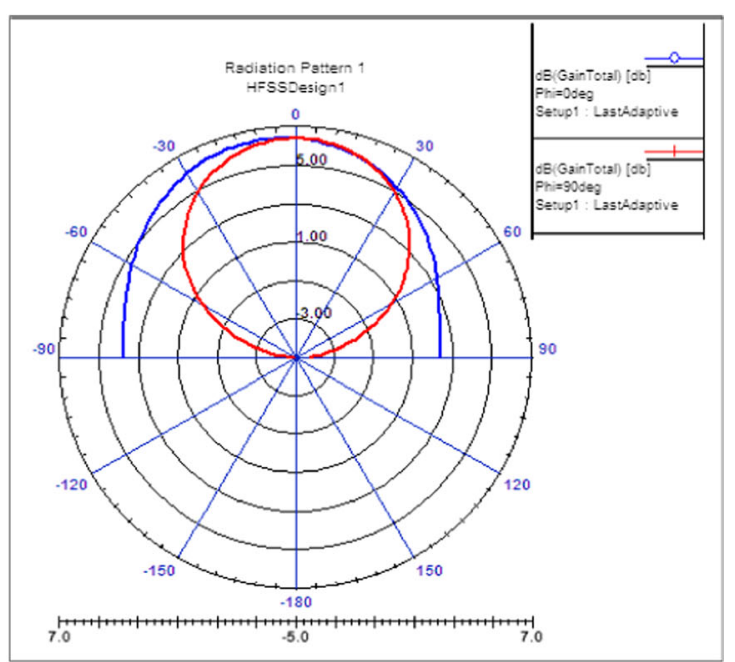

(b)

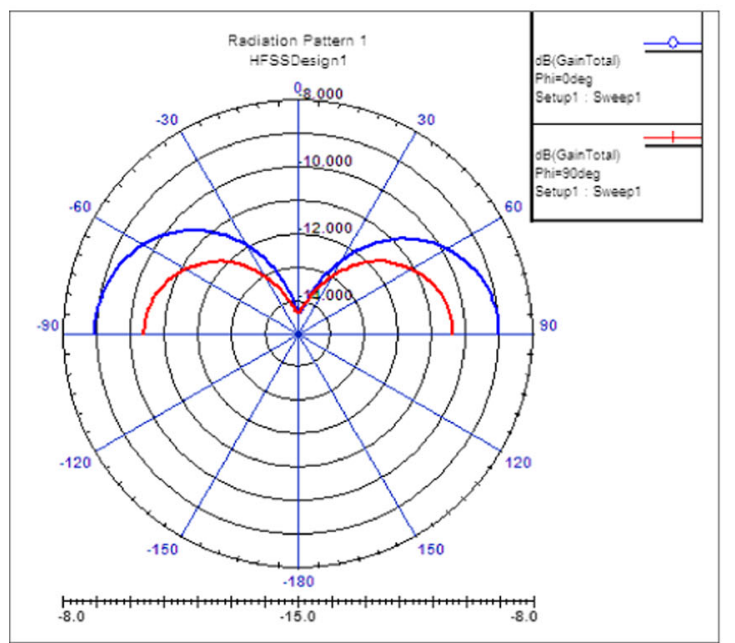

(c)

Fig. 7 The radiation pattern of square patch antenna loaded with SSRR. a Radiation pattern for RT Duroid substrate $\left(\varepsilon_{r}=2.2\right)$. b Radiation pattern for Rogers substrate $\left(\varepsilon_{r}=3.2\right)$. $\mathbf{c}$ Radiation pattern for Bakelite substrate $\left(\varepsilon_{r}=4.8\right)$ 
Table 3 Comparison of parameter results of square patch antenna loaded with SSRR on three substrates

\begin{tabular}{llll}
\hline & RT Duroid & Rogers RO 4232 & Bakelite \\
\hline Antenna dimensions (mm) & $49 \times 75 \times 32$ & $59 \times 56 \times 32$ & $59 \times 63 \times 32$ \\
Patch length and width (mm) & $40 \times 30$ & $40 \times 37$ & $30 \times 50$ \\
Optimal frequency (GHz) & 2.35 & 1.83 & 2.33 \\
Reflection coefficient (dB) & -22.98 & -22.38 & -28.82 \\
Bandwidth (MHz) & 500 & 400 & 300 \\
Maximal directivity (dB) & 6.97 & 6.55 & 7.24 \\
Gain (dB) & 6.94 & 6.46 & 6.57 \\
\hline
\end{tabular}

The Rogers substrate has low directivity of $6.55 \mathrm{~dB}$ compared to RT Duroid substrate has the maximum directivity of $6.97 \mathrm{~dB}$, while the patch antenna with SSRR has a substrate Bakelite who is not directive and this is due to the variation of the size of the antenna; increase in the length $L$ and decrease the width $W$. Also, Bakelite has the biggest dielectric constant among the three substrates.

\subsection{Radiation pattern}

Simulation results of the radiation a pattern of the antenna loaded with SSRR for three substrates are presented in figure show both the E-plane and H-plane radiation patterns.

Figure 7 shows the radiation pattern of the three antennas. It is clear from Fig. 7a, b that the radiation is directed which the energy radiated is concentrated in the main lobe.

The radiation pattern for RT Duroid substrate is constituted a single main lobe gain and 6.94 and $6.46 \mathrm{~dB}$ for Roger substrate. Distribution of radiation patterns makes this structure a good candidate for the antennas used for applications of $\mathrm{S}$-band. The patch antenna radiation pattern using the Bakelite as substrate is very similar to that of a dipole fed in the middle. Note that the radiation is very low in the axis of the antenna and maximum in the plane perpendicular to the antenna and not from the middle. Its gain reaches a value of $6.57 \mathrm{~dB}$.

From the comparison in Table 3, it has been concluded that with the increase in relative permittivity of substrate material performance (in terms of reflection coefficient and directivity) of patch antenna can be enhanced. We remark that the patch antenna use the Bakelite as a substrate is well suited and it resonates at the right frequency. The simulation confirmed the resonant frequency of the basic patch at $2.33 \mathrm{GHz}$ and a proper adaptation of $-28.82 \mathrm{~dB}$ but with a narrow bandwidth of $300 \mathrm{MHz}$.

\section{Conclusion}

In this paper, square patch antenna loaded with SSRR were studied and simulated. Several types of substrates were used, specifically, RT Duroid, Rogers RO 4232 and Bakelite. The performance of patch antenna is effected by its structure and dimensions, but the substrate material has also significant role in analyzing patch antenna performance. All substrates are compatible for S-band communications applications. Good enhancement, on both gain and directivity, is obtained by employing the array metamaterial techniques.

Open Access This article is distributed under the terms of the Creative Commons Attribution 4.0 International License (http://creativecomm ons.org/licenses/by/4.0/), which permits unrestricted use, distribution, and reproduction in any medium, provided you give appropriate credit to the original author(s) and the source, provide a link to the Creative Commons license, and indicate if changes were made.

\section{References}

[1] Thankachan, S., Mohan, S., Anil, A., Alisha, S., Nair, A.R.: Size reduction of bluetooth antenna: CSRR based patch concept. Int. J. Inf. Comput. Technol. 4(8), 805-810 (2014). ISSN 0974-2239

[2] Smith, D., Padilla, W., Wier, D., Nemat-Nasse, S., Schultz, S. Composite medium with simultaneously negative permeability and permittivity. Phys. Rev. Lett. 84, 4184-4187 (2000)

[3] Dogan, E., Unal, E., Kapusuz, D., Karaaslan, M., Sabah, C.: Microstrip patch antenna covered with left handed metamaterial. ACES J. 28(10), 999-1004 (2013)

[4] Marqué, R., Medina, F., Idrissi, R.R.-E.: Role of bianisotropy in negative permeability and left handed metamaterials. Phys. Rev. B Condens. Matter 65, 144441-144446 (2002)

[5] Baena, J.D., Bonche, J., Martin, F., Marqués, R., Falcone, F., Lopetegi, T., Laso, M.A.G., Garcia, J., Gil, I., Sorolla, M.: Equivalent-circuit models for split-ring resonators and complementary split-ring resonators coupled to planar transmission lines. IEEE Trans. Microwave Theory Tech. 53(4), 1451-1461 (2005)

[6] Falcone, F., Lopetegi, T., Baena, J.D., Marqué, R., Martin, F., Sorolla, M.: Effective negative- $\varepsilon$ stop-band microstrip lines based on complementary split ring resonators. IEEE Microwave Wirel. Compon. Lett. 14(6), 280-282 (2004)

[7] Elkamchouchi, H.M., Sheshtawy, A.A., Almahallawy, A.I.: Study and investigation of complementary split ring resonators (CSRR) metamaterials and its application in microstrip antenna design. Int. J. Appl. Eng. Res. 11(4), 2791-2795 (2016). ISSN 0973-4562

[8] Burokur, S.N.: Mise en œuvre de métamatériaux en vue d'application aux circuits microondes et aux antennes. Université Nantes, Thèse de doctorat (2005) 
[9] Saleh, A.A., Abdullah, A.S.: A novel design of patch antenna loaded with complementary split-ring resonator and L-shape slot for (WiMAX/WLAN) applications. Int. J. Wirel. Microwave Technol. 3, 16-25 (2014)

[10] sharan, R.K., Sharma, S.K., Gupta, A., Chaoudhary, R.K.: An edge tapered rectangular patch antenna with parasitic stubs and slot for wideband applications. Wirel. Pers. Commun. 86, 12131220 (2016)

[11] Mahmoodian, O.: Enhancing microstrip patch antenna performance by using high impedance surfaces (HIS). Bull. Env. Pharmacol. Life Sci. 5(6), 11-14 (2016)

[12] Kaur, G., Goyal, E.S.: To study the effect of substrate material for microstrip patch antenna. Int. J. Eng. Trends Technol. (IJETT) 36(9), 490-493 (2016)

[13] Thourel, L.: Calcul et conception des dispositifs en ondes centimétriques et millimétriques, vol. 2. Les Antennes, Cepadues (1990)

[14] Thakur, R., Kumar, R.: Design and simulation of metamaterial in compact broadband microstrip patch antenna for wireless router. Int. J. Adv. Res. Electron. Commun. Eng. (IJARECE), 4(6), (2015). ISSN: 2278-909X

[15] Nornikman, H., Ahmad, B.H., Abd Aziz, M.Z.A., Othman, A.R.: Effect of single complementary split ring resonator structure on microstrip patch antenna design. In: IEEE Symposium on Wireless Technology and Applications (ISWTA), September 23-26, Bandung Indonesia (2012)

[16] Afridi, M.A.: Microstrip patch antenna-designing at $2.4 \mathrm{GHz}$ frequency. Biol. Chem. Res. 20, 128-132 (2015)

[17] Ramna, A.S.S.: Design of rectangular microstrip patch antenna using particle swarm optimization. Int. J. Adv. Res. Comput. Commun. Eng. 2(7), 2918-2920 (2013)

[18] Vera-Dimas, J.G., Tecpoyotl-Torres, M., Vargas-Chable, P., Damián-Morales, J.A., Escobedo-Alatorre, J., Koshevaya, S.: Individual patch antenna and antenna patch array for Wi-Fi communication. Center for Research of Engineering and Applied Sciences (CIICAp), Autonomous University of Morelos State (UAEM) 62209, Av. Universidad No. 1001, Col Chamilpa, Cuernavaca, Morelos, México

[19] Maruf Ahamed, Md., Bhowmik, K., Al Suman, A.: Analysis and design of rectangular microstrip patch antenna on different resonant frequencies for pervasive wireless communication. Int. J. Sci. Technol. Res. 1(5) (2012)

[20] Kumar, S., Gupta, H.: Design and study of compact and wideband microstrip U-slot patch antenna for Wi-Max application. IOSR J. Electron. Commun. Eng. (IOSR-JECE) e-ISSN: 2278-2834, pISSN: 2278-8735. 5(2), 45-48. www.iosrjournals.org (2013)

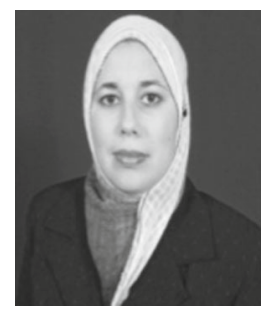

A. Bendaoudi received her Dipl.-ing. degree in Electronics from the Electronics Institute of University of Djillali Liabes, Sidi BelAbbes, Algeria, in 2001. Then she received her M.Sc. and Ph.D. from the Department of Electronics, University of Djillali Liabes, Sidi Bel-Abbes, Algeria, in the year 2005 and 2014, respectively. Since 2010 she is working as professor of Electronics department, University of Djillali Liabes, Algeria. She presented the research papers in National and International conferences in Algeria and abroad. Her areas of interest are microwave antennas and photonics.

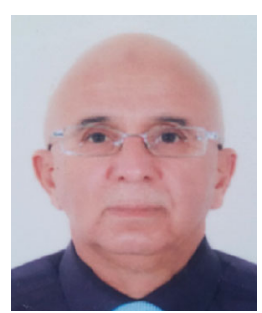

Z. Mahdjoub received the Dipl.-Ing. degree in Electronics from the Electronics Institute of USTO of ORAN, Algeria, in 1982, the Diploma of Advanced Studies, from The National Polytechnic Institute of GRENOBLE, France, in 1983, and the Ph.D. degree from the University of Claude Bernard de LYON I, France, in 1987. Since 1988 to 1991 , he was the President of the Scientific Council of the Electronics Institute, University of Djillali Liabes, Sidi BelAbbes, Algeria. Since 1988, he is involved in research on microwave, telecommunications and photonics. Since 1998 to 2006, he was the head of electronics department, University of Djillali Liabes. He is now full professor and Vice Dean of Post Graduation of the Electrical engineering Faculty at the same University. 